\title{
KAJIAN SASTRA NOVEL "LALITA" KARYA AYU UTAMI MELALUI PENDEKATAN PSIKOLOGI SASTRA
}

\author{
Ghaida Zukhruf Tsaniyatsnaini ${ }^{\boxplus}$ \\ ${ }^{1}$ Institut Agama Islam Negeri (IAIN) Salatiga \\ 'ghaidazukhruf@gmail.com
}

\begin{abstract}
The novels produced by the authors always display characters who have certain characters so that it can be said that the novel also describes the human psyche, even though the author only shows the character in fiction. The purpose of this study is to examine Ayu Utami's Lalita Novel by using a psychology of literature approach to examine psychologically the characters in the novel. This research was conducted using descriptive qualitative research. The results of this study, namely the mental condition of Lalita, the main character affected by internal conflict and external conflict. Lalita's most basic personality structure, in the form of id is very strong. The encouragement of ID which resulted in Lalita's ego continued to rise and peak resulted in him being filled with the nature and desire that was never satisfied to feel happiness and comfort. However, the events of robbery and rape in a more painful sense make his conscience open and this time the superego in his soul is able to defeat his id and ego.
\end{abstract}

Keywords: novel, psychology of literature, approach, Ayu Utami

\begin{abstract}
Abstrak : Novel yang dihasilkan oleh para pengarang selalu menampilkan tokoh yang memiliki karakter tertentu sehingga dapat dikatakan bahwa novel juga menggambarkan kejiwaan manusia, meskipun pengarang hanya menampilkan tokoh itu secara fiksi. Tujuan penelitian ini adalah mengkaji Novel Lalita karya Ayu Utami dengan menggunakan pendekatan psikologi sastra untuk menelaah secara psikologi tokoh-tokoh dalam novel tersebut. Penelitian ini dilaksanakan menggunakan penelitian kualitatif deskriptif. Hasil penelitian ini, yaitu kondisi kejiwaan Lalita, tokoh utama yang dipengaruhi oleh konflik internal dan konflik eksternal. Struktur kepribadian Lalita yang paling mendasar, berupa $i d$ sangat kuat. Dorongan id yang mengakibatkan ego Lalita terus meninggi dan memuncak mengakibatkan dirinya dipenuhi oleh sifat dan keinginan yang tidak pernah puas merasakan kebahagiaan dan kenyamanan. Akan tetapi, peristiwa perampokan dan pemerkosaan dalam arti yang lebih menyakitkan membuat hati nuraninya terbuka dan kali ini superego dalam jiwanya mampu mengalahkan id dan ego-nya.
\end{abstract}

Kata Kunci : novel, psikologi sastra, pendekatan, ayu utami 
Volume 1, Nomor 2, Juli 2019

ISSN 2655-3031 (P), 2655-7851 (O)

\section{Pendahuluan}

Novel merupakan sebuah totalitas yang bersifat artistik. Sebagai sebuah totalitas, novel mempunyai bagian-bagian, unsur-unsur yang saling berkaitan satu dengan yang lain secara erat dan saling menggantungkan. Novel dibangun atas unsur ekstrinsik dan intrinsik. Novel mengandung tema, amanat, karakteristik tokoh, alur, latar cerita, dan sudut pandang cerita (point of view). Selain itu, setiap novel senantiasa menawarkan pesan moral tersampaikan melalui cerita, sikap, dan tingkah laku tokoh-tokohnya. Novel yang dihasilkan oleh para pengarang selalu menampilkan tokoh yang memiliki karakter tertentu sehingga dapat dikatakan bahwa novel juga menggambarkan kejiwaan manusia, meskipun pengarang hanya menampilkan tokoh itu secara fiksi.

Endraswara (2011:96) menyimpulkan bahwa karya sastra yang dipandang sebagai fenomena psikologi akan menampilkan aspek-aspek kejiwaan melalui tokoh-tokoh yang terdapat dalam teks jika karya tersebut berbentuk prosa. Ilmu sastra dan psikologi juga tidak dapat dilepaskan dari pengkajian dan telaah sastra. Sastra ditempatkan sebagai hasil aktivitas dan ekspresi pengarang. Sementara itu, studi psikologi menempatkan pengarang sebagai tipe atau pribadi. Wellek dan Warren (2014:90) berpendapat bahwa psikologi sastra juga merupakan studi proses kreatif dan menelaah tentang tipe, hukum-hukum psikologi yang diterapkan pada karya sastra. Sejalan dengan itu, psikologi sastra juga mempelajari dampak sastra bagi para pembaca. Oleh karena itu, kajian psikologi sastra dapat membantu peneliti dalam meninjau karya sastra agar menjajaki polapola yang belum terjamah sebelumnya sehingga hasilnya merupakan kebenaran yang mempunyai nilai-nilai artistik yang dapat menambah koherensi dan kompleksitas karya sastra tersebut.

Karya sastra yang berbentuk fiksi, seperti novel, selalu mempunyai beragam kisah, tujuan pada cerita yang terdapat di dalamnya. Salah satu syarat sebuah novel yang dapat dikatakan baik adalah novel yang bisa membuat pembacanya ikut merasakan berada dalam cerita dan bisa larut dalam kisah yang diceritakan. Salah satu novel yang memiliki nilai-nilai pendidikan yang tinggi adalah novel-novel karya Ayu Utami. Selain itu, banyak pula novel yang ditulis oleh Ayu Utami yang memiliki sisi kelebihan dan dapat dikaji secara feminisme maupun secara psikologi sastra. Selain itu, penulis novel lebih menonjolkan karakter watak-watak tokoh dalam cerita novel dan mengembangkan konflik-konflik cerita yang begitu pelik mewarnai kisah novelnya. Novel yang peneliti pilih adalah novel Lalita yang merupakan novel kedua dari seri novel Bilangan Fu. Novel Lalita karya Ayu Utami menawarkan sebuah kisah yang berhubungan dengan sebuah pemikiran logika, wawasan khazanah budaya, dan pesan yang mendalam mengenai kehidupan. Oleh karena itu, fokus penelitian ini mengkaji secara psikologi tokoh Lalita dan juga tokoh lainnya.

\section{Metode Penelitian}

Penelitian ini dilaksanakan dengan menggunakan penelitian kualitatif deskriptif. Metode kualitatif berfokus pada data alamiah, data dalam hubungannya dengan konteks keberadaannya. Metode ini melibatkan gejala-gejala sosial yang relevan. Dalam penelitian karya sastra, akan dilibatkan pengarang dan di mana lingkungan sosial pengarang tersebut berada. Metode deskriptif dilaksanakan dengan mendeskripsikan fakta-fakta yang ada kemudian disusun dengan analisis. Secara etimologis, deskripsi dan analisis memiliki pengertian menguraikan, memberikan pemahaman dan penjelasan secukupnya (Ratna, 2004: 47-53)

Penelitian ini menggunakan dua sumber data, yaitu teks novel Lalita yang ditulis oleh Ayu Utami dan juga buku-buku literatur yang relevan dengan penelitian. Teknik pengambilan sampel yang 
Volume 1, Nomor 2, Juli 2019

ISSN 2655-3031 (P), 2655-7851 (O)

digunakan adalah purposive sampling, yaitu sumber data yang digunakan tidak mewakili populasinya, tetapi informasinya, dengan akses tertentu yang dianggap memiliki informasi yang berkaitan dengan permasalahannya secara mendalam dan dapat dipercaya menjadi sumber daya yang mantap (Sutopo, 2006:64). Metode yang digunakan, yaitu analisis dokumen dan wawancara secara mendalam. Validitas data penelitian ini dengan menggunakan trianggulasi sumber atau data yang berarti melakukan cek data dokumen dan wawancara secara mendalam.

Kemudian, teknik analisis data yang digunakan adalah teknik analisis interaktif Miles dan Huberman. Teknik analisis data ini memiliki tiga komponen, yaitu reduksi data, penyajian data, dan penarikan kesimpulan (Miles dan Huberman (dalam Sutopo), 2006: 96). Model analisis interaktif ini berjalan beriringan dengan pelaksanaan pengumpulan data. Ketika peneliti menyusun catatan secara lengkap, reduksi dibuat, kemudian peneliti melanjutkan tahapan pengembangan bentuk susunan penyajian data yang sifatnya sementara. Pada saat tahapan penarikan kesimpulan, apabila ada data yang bertambah yang berkaitan dengan permasalahan dalam penelitian, maka kesimpulan juga dapat berubah. Bertambahnya data melalui verifikasi yang berlangsung secara berkesinambungan akan menghasilkan kesimpulan yang bersifat grounded (Sutopo, 2006: 120).

\section{Hasil dan Pembahasan}

Tokoh utama dalam novel ini adalah Lalita. Ia lebih mendominasi dan diceritakan terus-menerus dalam cerita. Penggambaran karakter tokoh detail dan utuh sehingga membuktikan bahwa tokoh tersebut adalah tokoh utama dalam novel. Hal ini sejalan dengan pendapat Nurgiyantoro (2005:176) yang menyatakan tokoh utama merupakan tokoh yang ditampilkan secara terus menerus atau paling sering diceritakan dalam sebuah cerita.
Tokoh tambahan yang terdapat dalam novel adalah Yuda, Parang Jati, Marja, Oscar, Janaka, Jisheng, Anshel, dan lain-lain. Dalam novel ini, mereka berperan sebagai tokoh pembantu dan menjadi penengah di dalam jalannya cerita. Selain tokoh utama, terdapat pula tokoh tambahan dan tokoh pembantu dalam novel ini, yaitu tokoh yang sesekali muncul tanpa pembahasan yang spesifik dalam penggambaran wataknya. Kemudian, dikisahkan bahwa watak dari pemeran utama, yaitu Lalita memiliki sifat yang pintar, berkemauan keras, tidak mudah menyerah, cenderung sombong, dan jauh di dasar hatinya memiliki kebaikan serta kesucian dalam dirinya. Penampilan Lalita yang berdandan vulgar dan berlebihan membuat dirinya tidak disukai perempuan lainnya. Namun, Lalita tidak pernah ambil pusing terhadap hal tersebut. Berbagai konflik yang ada dalam kehidupannya membawanya menuju sebuah keputusan yang sangat mulia. Pada akhirnya, dia memutuskan untuk melepaskan semua atribut duniawinya dengan mengabdikan diri sepenuhnya untuk beribadah. Lalita menjadi seorang biksuni.

Tokoh Yuda memiliki sifat yang ceroboh, terbukti dari beberapa sikap yang dilakukan oleh Yuda yang mengakibatkan terjadinya peristiwa-peristiwa fatal. Sementara itu, tokoh Parang Jati merupakan tokoh yang memiliki sifat dan sikap yang menunjukkan moral yang tinggi, seperti dalam kutipan berikut.

Ia memutar-mutar ulang percakapannya dengan Parang Jati. Barangkali karena anak itu mewakili moral yang tinggi. Tapi mungkin juga karena dialog dengannya memberi kenikmatan untuk dikenang. Barangkali manusia tidak punya kapasitas untuk mengampuni. Yang bisa dilakukannya hanyalah berdamai... (Lalita, 2012:208).

Pengarang menyampaikan amanat atau pesan moral melalui tokoh Parang Jati, sifatnya yang baik, pemaaf, suka menolong, 
Volume 1, Nomor 2, Juli 2019

ISSN 2655-3031 (P), 2655-7851 (O)

dan sering mengalah. Sikap-sikapnya menempati posisi terpenting dalam novel Lalita sehingga perannya dalam membawakan pesan atau amanat tersampaikan. Hal itu sejalan dengan pendapat Nurgiyantoro (2005:165) bahwa tokoh adalah orang-orang yang ditampilkan dalam suatu karya naratif atau drama yang oleh pembaca ditafsirkan memiliki kualitas moral dan kecenderungan tertentu seperti yang diekspresikan dalam ucapan dan apa yang dilakukan dalam tindakan.

Tokoh Marja juga mengajarkan kita untuk berhati-hati dalam melakukan suatu hal agar nantinya kita tidak merasakan kekecewaan yang mendalam. Sifat Oscar juga dapat mewakili seorang pria yang baik karena mampu menjaga perasaan kekasihnya. Sementara itu, tokoh Jisheng merupakan tokoh yang kurang baik karena selama ini dia harus berbohong demi misi rahasianya, tetapi di dasar hatinya memiliki rasa kasih sayang. Tokoh Anshel diceritakan di bagian tengah novel Lalita, digambarkan bahwa Anshel memiliki sifat yang pintar dalam dunia spiritual dan intelektual. Lain halnya dengan tokoh Janaka yang mewakili tokoh antagonis karena menentang tokoh utama. Sikap yang dilakukan Janaka merupakan sikap yang negatif, digambarkan dengan karakternya yang sangat serakah.

\section{Struktur Kejiwaan Psikologis Tokoh Utama dalam Novel Lalita}

Freud (mengutip simpulan Minderop, 2011:20) membahas pembagian psikisme manusia menjadi tiga bagian. Pertama, id. Id terletak di bagian tak sadar yang merupakan reservoir kompulsi dan menjadi sumber energi psikis. Kedua, ego, terletak di antara alam sadar dan tak sadar. Ketiga, superego, terletak sebagian di bagian sadar dan sebagian lagi di bagian tak sadar.

Psikologi merupakan analisis lanjutan dari perwatakan tokoh Lalita dalam novel Lalita. Konflik yang dialami oleh Lalita tidak hanya berasal dari dalam dirinya, tetapi juga konflik ekternal yang mendominasi kisah hidupnya. Kondisi kejiwaan Lalita dapat dipastikan sangat terganggu oleh konflik-konflik yang dialaminya. Lingkungan terkecil yang dimiliki Lalita, yaitu keluarga, sudah mulai tidak baik. Lalita merasa tidak nyaman dengan perlakuan kakak kandungnya atau saudara kembarnya. Berdasar dan berawal dari sanalah Lalita memutuskan untuk hidup sendiri jauh dari kakaknya.

Lalita memiliki kekuatan id yang mendorong dirinya untuk mendapat perasaan yang nyaman dan senang dengan menjadi sebagai pusat perhatian semua orang. Lebih lanjut lagi diceritakan bahwa Lalita juga memiliki dorongan id untuk menguasai Yuda meskipun saat itu Lalita sudah memiliki kekasih yang bernama Oscar. Kali ini egonya yang bekerja sebagai perdana menteri dalam dirinya meluap dan menggebu sehingga jalan yang ditempuh Lalita untuk mendapatkan id pun tercapai.

Hal ini sejalan dengan pendapat Endraswara yang menyatakan bahwa id merupakan wadah dari jiwa manusia yang berisi dorongan primitif. Dorongan primitif adalah dorongan yang ada pada diri manusia yang menghendaki untuk segera dipenuhi atau dilaksanakan keinginan atau kebutuhannya. Apabila dorongan tersebut terpenuhi dengan segera, maka akan menimbulkan rasa senang, puas, serta gembira. Sebaliknya, apabila tidak dipenuhi atau dilaksanakan dengan segera, maka akan terjadi hal yang sebaliknya. Id adalah sistem kepribadian manusia yang paling dasar. Id merupakan aspek kepribadian yang paling gelap dalam bawah sadar manusia yang berisi insting dan nafsu-nafsu tak kenal nilai dan agaknya berupa "energy buta". (Endraswara, 2008:101). Berdasarkan pengertian tersebut, bahwa id merupakan dorongan dari aspek biologis yang terjadi secara spontan.

Bagian awal novel Lalita memang menampilkan betapa id dan ego Lalita sangat menguasai dirinya. Bahkan, Lalita belum tersentuh hati nuraninya sedikit pun saat dirinya masih dikuasai oleh id dan ego. Hal itu sejalan dengan pendapat Minderop 
Volume 1, Nomor 2, Juli 2019

ISSN 2655-3031 (P), 2655-7851 (O)

(2011:22) bahwa id dan ego tidak memiliki moralitas karena keduanya ini tidak mengenal nilai baik dan buruk. Namun, Lalita juga memiliki mekanisme bertahan yang dia lakukan untuk meredam konflik yang meledak dan semakin memporakporandakan masalahnya. Misalnya, saat impuls agresif yang ditunjukkan kepada orang lain dianggap aman untuk diserang, Lalita lebih memilih untuk mencari objek pengganti yang lain.

Beberapa konflik yang mendominasi kehidupan Lalita membuat dorongandorongan negatifnya semakin memuncak. Pada akhirnya, dapat disimpulkan bahwa Lalita merupakan cermin manusia yang memiliki kemauan keras bahkan tidak dapat terkalahkan. Namun, pada suatu hari superego yang mengacu pada nilai-nilai masyarakat juga mulai hidup dalam jiwanya. Hal tersebut dibuktikan pada kasus percintaan Lalita dengan Yuda. Hal tersebut dapat dibuktikan dalam kutipan berikut.

"Kamu punya pacar Yuda?" Yuda
tersenyum salah tingkah. "kamu
punya pacar!" nadanya agak marah.
"Y-ya" "Kamu mencintainya?" "S-
saya m-merasa...ya, saya saying
padanya." "Kamu kurang ajar."
(Lalita, 2012:62).

Berawal dari sanalah superego Lalita tersentuh dan hati nurani menempatkan jiwanya jika dihadapkan pada situasi sebagai kekasih Yuda pastilah sangat tersakiti. Pada kenyataannya, Lalita telah berselingkuh dengan kekasih perempuan lain dan hal tersebut juga bertentangan dengan nilai moral di masyarakat maupun batin dalam jiwanya.

Perseteruannya dengan Janaka tentang buku indigo juga semakin memuncak. Hal tersebut berujung pada perampokan dan pemerkosaan dalam arti yang lebih menyakitkan di rumah Lalita, hilangnya buku indigo yang diincar Janaka. Setelah kejadian itu, Lalita menghilang dan di akhir cerita diceritakan bahwa Lalita kini menjadi seorang biksuni. Keputusan Lalita ini dipengaruhi oleh kuatnya superego dalam jiwa Lalita. Tokoh Lalita memiliki hati nurani dan moral yang tinggi meskipun semua terpaparkan di dalam bagian akhir novel ini. Id dan ego Lalita yang dulunya muncul sangat tinggi kini mampu terhapus oleh superego-nya. Semua konflik yang mewarnai kehidupannya membawa pada proses penyempurnaan hidupnya, meninggalkan segala atribut duniawinya menuju jiwa yang penuh dengan ketenangan, dan kenyamanan abadi.

Hal yang dialami Lalita, tokoh utama, sejalan dengan pendapat Endraswara yang menyatakan bahwa superego adalah sistem kepribadian yang berisi nilai-nilai aturan yang bersifat evaluatif (menyangkut baik dan buruk). Superego merupakan penyeimbang dari id. Semua keinginankeinginan id sebelum menjadi kenyataan, dipertimbangkan oleh superego. Apakah keinginan id itu bertentangan atau tidak dengan nilai-nilai moral yang ada dalam masyarakat. Superego berisi nilai-nilai moral yang ditanamkan pada diri seseorang. Pada dasarnya, superego sama dengan kesadaran. Aspek sosiologi kepribadian, merupakan wakil dari nilai-nilai tradisional serta cita-cita masyarakat sebagaimana ditafsirkan orangtua kepada anak-anaknya, yang dimasukkan dengan berbagai perintah dan larangan (Endraswara, 2008:101).

\section{Nilai-Nilai Pendidikan dalam Novel Lalita}

Nilai-nilai pendidikan yang akan dibahas dalam penelitian ini, antara lain: nilai pendidikan agama, nilai pendidikan moral, nilai pendidikan sosial, nilai pendidikan budaya, yang terkandung dalam novel Lalita. Sejalan dengan pendapat Mangunwijaya (Nurgiyantoro, 2005: 326), agama lebih menunjukkan kebaktian kepada Tuhan dengan hukum-hukum resmi. Oleh karena itu, agama sangat berkaitan dengan keimanan di lubuk hati. Seperti dalam novel Lalita dikisahkan mengenai tokoh ayah Anshel yang jauh dari agama dan merasa bahwa agama tidak boleh mendominasi di 
Volume 1, Nomor 2, Juli 2019

ISSN 2655-3031 (P), 2655-7851 (O)

keluarga mereka. Namun, kenyataannya kekekalan sebuah ilmu pasti akan tumbang juga dan sepintar apa pun, semua orang pasti akan meninggal, kembali ke Sang Pencipta.

Agama mengajarkan tentang keyakinan kepada Tuhan. Nilai pendidikan agama berkaitan dengan ajaran tentang keesaan Tuhan, kekuasaan-Nya, percaya akan adanya Tuhan, rasa syukur atas nikmat yang dianugerahkan-Nya. Keyakinan kepada Tuhan yang terdapat dalam diri manusia akan berpengaruh terhadap perilakunya di kehidupan sehari-hari. Nilai agama juga dijadikan sudut pandang yang mengikat manusia dengan Tuhan pencipta alam dan seisinya. Nilai-nilai agama bertujuan untuk mendidik agar manusia lebih baik. Dalam novel Lalita, salah satu tema yang dibahas mengenai sebuah keyakinan. Keyakinan tersebut membahas sebuah perjalanan hidup spiritual anak manusia yang akhirnya menemukan ketenangan dalam hidupnya. Seperti yang diimplikasikan pada tokoh Lalita di akhir cerita yang mengisahkan bahwa dirinya dituntun oleh superego yang melekat pada jiwanya.

Moral merupakan pandangan pengarang tentang nilai-nilai kebenaran dan pandangan itulah yang ingin disampaikan kepada pembaca. Nilai pendidikan moral mewarnai kisah dalam novel Lalita yang ditunjukkan pada konflik yang terjadi dalam novel ini. Melalui tokoh Parang Jati, berbagai nilai pendidikan moral terurai dari sikap yang dipengaruhi oleh karakter yang dimilikinya. Sikap Parang Jati mewakili orang bermoral tinggi. Cara berpikir Parang Jati dalam menyelesaikan setiap persoalan menunjukkan bagaimana sifat baik tertanam dalam dirinya. Kemudian, melalui tokoh Janaka tercermin betapa kejahatan dan jiwa manusia juga sulit dipisahkan. Hal itu berbanding terbalik dengan Parang Jati karena semua yang ada dalam diri Janaka sangat bertentangan dengan kebenaran nilai moral.
Nilai sosial berkaitan dengan perilaku sosial dan tata cara hidup sosial. Perilaku sosial berupa sikap seseorang terhadap peristiwa yang terjadi di sekitarnya, yang berhubungan dengan orang lain, cara berpikir, dan hubungan sosial bermasyarakat antarindividu. Rosyadi (1995: 80) berpendapat bahwa nilai sosial yang ada dalam karya sastra dapat dilihat dari cerminan kehidupan masyarakat yang diinterpretasikan. Sejalan dengan pengertian tersebut, nilai pendidikan sosial akan menjadikan manusia sadar akan pentingnya kehidupan berkelompok dalam ikatan kekeluargaan antara satu individu dengan individu lainnya. Keseimbangan kehidupan masyarakat tercermin dalam kisah yang sangat memprihatinkan, seperti dijelaskan dalam novel bagaimana keadaan Kota Jakarta yang penuh dengan sekat-sekat perbedaan.

Kehadiran nilai pendidikan budaya merupakan salah satu jenis nilai pendidikan yang penting dalam novel Lalita. Cerita novel yang hanya berkisah mengenai peninggalan sejarah seperti halnya Candi Borobudur maupun penyebab konflik, yaitu buku indigo mewakili betapa pentingnya mengahargai peninggalan sejarah tersebut. Cara yang ditempuh untuk menghargainya dapat ditempuh dengan merawat dan melestarikan budaya tersebut. Nilai pendidikan kebudayaan yang lainnya juga terlihat pada kekayaan budaya Jawa seperti alat musik gamelan yang diceritakan di bagian tengah novel Lalita.

\section{Simpulan}

Berdasarkan hasil analisis dan pembahasan di atas, dapat disimpulkan bahwa kerkaitan antarunsur yang membangun novel Lalita sangat kuat dan menjadikan cerita yang disajikan dalam novel Lalita penuh dengan makna nilai pendidikan. Keterkaitan antarunsur di dalamnya membangun keselarasan antara tema, amanat, alur, latar, bahasa yang dapat mendukung kemunculan nilai pendidikan dalam novel. 


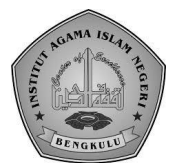

Tokoh utama dalam novel Lalita adalah Lalita. Lalita memiliki perwatakan yang keras dan tidak mudah menyerah. Tokoh lain dalam novel Lalita antara lain: Yuda, Parang Jati, Marja, Oscar, Jisheng, Anshel, dan lain sebagainya. Tokoh Yuda memiliki watak yang bodoh dan cenderung ceroboh, Parang Jati memiliki sifat yang baik dan bermoral tinggi sehingga berbeda dengan Yuda. Perwatakan yang dimiliki Marja adalah lugu, polos, dan penuh pertimbangan dalam menentukan keputusannya. Oscar memiliki sifat penyayang, menjaga perasaan perempuan. Jisheng merupakan seseorang yang bersifat diam-diam menghanyutkan karena Jishenglah kunci dari hilangnya buku indigo. Sementara itu, Anshel memiliki sifat yang pandai dalam hal intelektual dan spiritual.

Kondisi kejiwaan Lalita dipengaruhi oleh konflik internal dan konflik eksternal yang mewarni kehidupan Lalita. Struktur kepribadian Lalita yang paling mendasar, berupa $i d$ sangat kuat. Dorongan id yang mengakibatkan ego Lalita terus meninggi dan memuncak mengakibatkan dirinya dipenuhi oleh sifat dan keinginan yang tidak pernah puas merasakan kebahagiaan dan kenyamanan. Akan tetapi, peristiwa perampokan dan pemerkosaan dalam arti yang lebih menyakitkan membuat hati nuraninya terbuka dan kali ini superego dalam jiwanya mampu mengalahkan $i d$ dan ego-nya.

\section{Daftar Pustaka}

Endraswara, S. 2008. Metodologi Penelitian Psikologi Sastra - Teori Langkah, dan Penerapannya. Yogyakarta: FBS Universitas Negeri Yogyakarta.

Endraswara, S. 2011. Metodologi Penelitian Sastra. Yogyakarta: CAPS.

Minderop, A. 2011. Psikologi Sastra: Karya Sastra, Metode, Teori, dan Contoh Kasusnya. Jakarta: Yayasan Pustaka Obor Indonesia.
Volume 1, Nomor 2, Juli 2019

ISSN 2655-3031 (P), 2655-7851 (O)

Nurgiyantoro, Burhan. 2005. Teori Pengkajian Fiksi. Yogyakarta: Gadjah Mada University Press.

Ratna, Nyoman Kutha. 2004. Teori, Metode dan Teknik Penelitian Sastra. Yogyakarta: Pustaka Belajar.

Rosyadi. 1995. Nilai-Nilai Budaya dalam Naskah Kaba. Jakarta: CV Dewi Sri.

Sutopo, H.B. 2006. Metodologi Penelitian Kualitatif: Dasar Teori dan Terapannya dalam Penelitian. Surakarta: Universitas Sebelas Maret.

Utami, Ayu. 2012. Lalita. Jakarta: Kepustakaan Populer Gramedia.

Wellek, R. dan Warren, A. 2014. Teori Kesusastraan (Terjemahan Melani Budianta). Jakarta: Gramedia. 